\title{
A INFLUÊNCIA CULTURAL NA DISSEMINAÇÃO DA VIOLÊNCIA DOMÉSTICA E PÚBLICA CONTRA A MULHER
}

THE CULTURAL INFLUENCE ON THE DISSEMINATION OF DOMESTIC AND PUBLIC VIOLENCE AGAINST WOMEN

\section{Delma Domingues Oliveira* Erika Leahy ${ }^{* *}$}

\begin{abstract}
Resumo:
O presente artigo busca analisar a influência da cultura patriarcal disseminada na sociedade, advinda nos primórdios, onde homens e mulheres desde a concepção, aceitavam um modelo preconcebido do seu destino e de suas funções na sociedade. O que se quer demonstrar é o fato de que em função dos estereótipos de gênero os papéis entre dominador e dominado foram aceitos e reproduzidos ao longo de milhares de centenas de anos, além de enfatizar que a violência de gênero contra a mulher é perpetuada graças à legitimação e aos mitos prescritos pela sociedade machista/patriarcal onde a posição subalterna de mulheres em relação à exploração e violência era admitida como um comportamento intrínseco dos homens e da sociedade, mas que aos poucos vem sendo combatida, principalmente a partir da Constituição de 1988, com alterações nas legislações voltadas à proteção de minorias.
\end{abstract}

Palavras-chave: Submissão. Violência doméstica contra mulher. Violência pública.

\begin{abstract}
:
This article seeks to analyze the influence of the patriarchal culture disseminated in society, originating in the early days, where men and women since conception, accepted a preconceived model of their destiny and their functions in society. What we want to demonstrate is the fact that due to gender stereotypes, the roles between dominator and dominated have been accepted and reproduced over thousands of hundreds of years, in addition to emphasizing that gender violence against women is perpetuated thanks to legitimacy and the myths prescribed by the male/patriarchal society where the subordinate position of women in relation to exploitation and violence was admitted as an intrinsic behavior of men and society, but which has been gradually combated, mainly since the 1988 Constitution, with changes in legislation aimed at protecting minorities.
\end{abstract}

Keywords: Submission. Domestic violence against women. Public violence.

" Pesquisadora do Cedmar-USP, Centro de Estudos em Direito do Mar "Vicente Marotta Rangel", e do GEPIM-USP, Grupo de Estudos sobre a Proteção Internacional de Minorias. Advogada.

** Graduanda na PUCPR. Membro do CEPIM-USP, Centro de Estudos sobre a Proteção Internacional de Minorias, do GPDI-UFRJ, Grupo de Pesquisa de Direito Internacional e do Neadi-PUCPR, Núcleo de Estudos Avançados em Direito Internacional e Sustentabilidade. E-mail de contato: erika.leahy3@gmail. com. 
Introdução

A partir da Constituição de 1988, nota-se um esforço interno brasileiro de proteção às minorias. Podemos destacar a proteção implementada pelo Código Penal, na tipificação do feminicídio, racismo, injúria racial, estupro, etc.; pelo Código Civil, que prevê o poder pátrio em igualdade para o pai e para a mãe, capacidade para pessoa com deficiência e leis esparsas; pela Lei Eleitoral que determina cota feminina nas eleições, além da proteção jurisprudencial, com o reconhecimento de união estável e casamento homoafetivo, tipificação da homofobia, determinação de que os recursos partidários devam ser proporcionais ao número de candidatas e a proteção constitucional, a qual se caracteriza como a de maior importância, vez que dá o tom para todo o entendimento jurídico no país.

Em diversos artigos, a Constituição deixa claro a proteção às minorias por meio de proteção à igualdade e à dignidade da pessoa humana. No art. $1^{\circ}$, III coloca a dignidade da pessoa humana como fundamento da República. Já no art. $3^{\circ}$, IV prevê como objetivo a promoção do bem de todos, sem preconceitos e discriminações. $\mathrm{O}$ art. $4^{\circ}$ eleva a princípio que deve reger a República, a prevalência dos Direitos Humanos e a autodeterminação dos povos. Enquanto o art. $5^{\circ}$, o mais famoso, prevê que todos são iguais perante a lei. Além desses, são observáveis diversos artigos na Constituição, que expressamente ou implicitamente protegem as minorias.

Observa-se, no entanto, que esse esforço apenas foi, e é, possível devido ao desenvolvimento internacional da proteção às minorias. No plano internacional, reconhece-se como primeiro empreendimento de proteção a Paz de Augsburgo em 1555, a qual estabeleceu a tolerância de Luterano no Sacro Império Romano. Após longos anos de proteção apenas às minorias religiosas, teve o Tratado de Paris em 1856, protegendo as minorias étnicas. Porém, os esforços continuavam restritos ao âmbito europeu. Depois da Primeira Guerra Mundial, o Tratado de Versalhes celebrou a paz e criou a Sociedade das Nações, a qual tinha função de proteger as minorias.

Com o fim da Sociedade das Nações e a Segunda Guerra Mundial tornouse evidente a necessidade de proteção às minorias bem mais efetivas, com ênfase ao ser humano. Assim, sobreveio a Declaração Universal dos Direitos Humanos, de 1948.

Desde então, passou-se a estabelecer uma proteção bem mais efetiva, diante de diversos meios, como a Declaração das Nações Unidas sobre Todas as Formas de Discriminação Racial, Convenção Internacional sobre a Eliminação de Todas as Formas de Discriminação Racial, Convenção para a Eliminação de Todas as Formas de Discriminação Contra as Mulheres (CEDAW), Princípios de Yogyakarta, entre outros.

Com esse avanço no âmbito da proteção, considerou-se de extrema importância o conceito de minorias. Houve diversas tentativas, mas nenhum satisfazia 
por completo o termo. Tentou-se conceituar com base na quantidade numérica, existência de certa tradição ou característica hereditária, a posição não dominante no Estado. Por fim, entende-se como minoria um conceito aberto, sendo, portanto, que há diversas características que o conceitua, desde posição não dominante no Estado até traços físicos ou culturais específicos autoconsciente. Mas, o mais importante, é que tenha um estigma social no grupo que compõe a minoria.

Dessa conceituação, insere-se as mulheres, que, apesar de quantitativamente não insignificante o número, sua representação foi sempre mínima e seus direitos muito limitados. Isso ocorre em virtude da sociedade patriarcal, a qual é traçada desde antes dos tempos bíblicos, e reforçada por várias religiões. Para uma mudança concreta na condição da mulher, que é vista socialmente como inferior à pessoa do gênero masculino, o Estado deve impor obrigações específicas, desde a previsão de igualdade, proibição de discriminação e violência de gênero, até programas de conscientização para efetiva transformação.

Dessa maneira, o presente artigo busca analisar a influência da cultura patriarcal disseminada na sociedade, advinda nos primórdios, onde homens e mulheres desde a concepção, aceitavam um modelo preconcebido do seu destino e de suas funções na sociedade.

O artigo utilizará do método hipotético-dedutivo e será elaborado por meio de pesquisas em fontes bibliográficas e jurisprudenciais quanto a casos internacionais. Inicialmente analisaremos o contexto histórico de submissão entre homem e mulher, especialmente em relação à demonstração dessa submissão pelas legislações. Feito isso, será explicada a proteção internacional às mulheres. Em seguida, passaremos ao estudo dos dados e de casos para demonstrar a eficácia da proteção. Posteriormente, será esclarecido a posição do homem como vítima da cultura patriarcal. Por fim, será exposto o que sustenta esse comportamento falocêntrico na sociedade contemporânea.

\section{Contexto histórico de submissão entre homem e mulher}

A violência de gênero contra a mulher tem sido possível graças à legitimação e aos mitos prescritos na sociedade, que chancelam a posição subalterna de mulheres e permitem a perpetuação da violência sob o amparo do Estado.

Deste modo, entender o passado deixado ao feminino pela cultura ocidental, defendido por um discurso heteronormativo e preconceituoso é categórico para o enfrentamento das desigualdades e suas consequências, acometidas diariamente às mulheres na sociedade.

Dessa forma, notamos a diferença entre homem e mulher estabelecida pela medicina segundo Laqueur (2001, p. 17): 
$\mathrm{O}$ antigo modelo no qual homens e mulheres eram classificados conforme seu grau de perfeição metafísica, seu calor vital, ao longo de um eixo cuja causa final era masculina, deu lugar, no final do século XVIII, a um novo modelo de dimorfismo radical, de divergência biológica. Uma anatomia e fisiologia de incomensurabilidade substituiu uma metafísica de hierarquia na representação da mulher com relação ao homem.

Outra corrente, vista em Hasse (2016), entende que a naturalização do universo feminino deu-se de modo biológico, no que diz desrespeito à capacidade de gestar, parir e amamentar, ou seja, na maternidade e acrescenta também o trabalho doméstico.

$\mathrm{Na}$ medida em que a determinação biológica parece justificar plenamente as questões sociais que envolvem esse corpo, ela passa a ser dominante, como explicação legítima e única sobre aqueles fenômenos. Daí decorrem ideias sobre a maternidade, o intuito maternal e divisão sexual do trabalho como atributos naturais e essenciais de gêneros na sociedade. Assim, a partir de então, a maternidade era traçada como destino único para todas as mulheres, portanto, segundo a autora, aquelas mulheres que não se tornavam mães praticamente eram invisíveis na sociedade no século XIX.

Aqui, podemos averiguar melhor o poder que o Estado exercia, ou que ainda exerce sobre o gênero feminino, no que diz respeito à reprodução biológica da espécie, ou seja, a mulher sendo vista simplesmente como mera reprodutora; mesmo que, em alguns lugares possa ser mente dominante, ainda sim, infelizmente continua sendo vista da mesma maneira.

Ao voltar os olhos para a história, obviamente não se encontra resposta única e linear para o momento em que houve e de como se desenvolveu o início da sociedade patriarcal.

Entende-se que originalmente a sociedade era organizada sob a forma matriarcal, pois não se tinha conhecimento do papel do homem no parentesco com as crias. Dessa forma, a mulher tinha um papel de extrema importância. Contudo, a partir do momento em que se tomou conhecimento da participação do homem na reprodução, foi estabelecido à mulher a exigência de fidelidade. (SANTIAGO, 2007).

Há registros tanto na Grécia antiga quanto em Roma que a sociedade já estava organizada sob os moldes patriarcais. A mulher encontrava-se restrita ao papel de criar os filhos e de cuidar de seus afazeres domésticos. (SANTIAGO, 2007). Única exceção era em Creta no período de 200 a.C. a 1400 a.C., em que a mulher era detentora de direitos. Até em Atenas, sociedade bem avançada, visto que foi a propulsora da democracia, somente os homens adultos eram considerados cidadãos. (HASSE, 2016, p. 30). 
Avançando-se na história, a sociedade feudal manteve as esposas sobre controles rigorosos, devido à constante ausência dos maridos a serviço das guerras. A dominância da religião cristã também contribuiu à sociedade falocêntrica, pois atribuíam à mulher a imagem de pecaminosas, responsáveis pelo desterro humano do paraíso, como outras religiões similarmente prescrevem.

A partir da Revolução francesa, no entanto, começa a ser questionada essa condição da mulher na sociedade. Assim, por ideais iluministas, declaração dos direitos dos homens, surgem os primeiros registros no Ocidente de luta feminista.

\section{Evolução Legislativa}

Tem-se que todo esse histórico de luta repercutiu também na esfera legislativa brasileira. Observa-se que as Ordenações Filipinas, que vigoraram até 1916, autorizavam ao marido aplicar punições corporais nas mulheres. Essa autorização foi revogada em 1916 com a entrada em vigor do Código Civil, porém este não conteve muitos avanços quanto à luta feminina. O referido Código previa no art. 186 a prevalência da vontade paterna quando ocorresse discórdia; determinava que a mulher casada era relativamente incapaz no art. $6^{\circ}$, inciso II; conferia ao pai o pátrio poder no art. 380; e no art. 242 restringia a prática de diversos atos da mulher sem autorização do marido, inclusive exercer qualquer profissão (inciso VII). (VERONESE, 2011).

Em 1932, houve avanço quanto ao direito ao voto. Todavia, esse era apenas facultativo para as mulheres, enquanto para os homens era obrigatório. Somente 14 anos depois tornou-se obrigatório para ambos os gêneros.

Em 1940, entrou em vigor o Código Penal, o qual previa que o crime de estupro apenas seria típico quando o ato era realizado contra mulher "honesta", e o estuprador poderia ter a punibilidade extinta, caso ele se casasse com a mulher estuprada. Apenas em 2005, com a Lei n. 11.106 foi abolida a expressão "mulher honesta" do Código Penal. (VERONESE, 2011).

Avançou-se em relação ao Código Civil em 1962, com o Estatuto da Mulher Casada, que retirou a condição de incapaz relativamente da mulher, bem como determinou condição de colaboradora na administração da sociedade conjugal e a possibilidade de a mulher trabalhar, sem autorização prévia do marido. Ainda, em 1977 a Lei do Divórcio deu a oportunidade aos cônjuges de pôr fim ao casamento. Em 1988, a Constituição da República previu em diversos dispositivos a igualdade entre os sexos, inclusive estabelecendo como direito fundamental no art. 5². (LEÃO; PEDROZO, 2018).

Um dos maiores marcos, contudo, ocorreu apenas no século 21, com a Lei Maria da Penha, em 2006, a qual disciplinou a violência doméstica, a fim de ter uma legislação mais forte quanto ao tema, e a Lei do Feminicídio, a qual criou uma nova 
qualificadora para o tipo penal, que se mostrou de extrema importância em relação aos alarmantes números de morte das mulheres pela condição de serem mulheres.

\section{Proteção Internacional}

Esses avanços que ocorreram na ordem interna, além de traduzirem a luta feminina socialmente, demonstram a adoção de diversos tratados pelo Brasil, que impuseram ao país a mudança legislativa. Primeiramente, a Declaração de 1948, apesar de não ser obrigatório o cumprimento, estabelece a proteção do Direito Internacional dos Direitos Humanos, dispondo sobre direito de igualdade. Ainda, o Pacto Internacional sobre Direitos Civis e Políticos confere igualdade aos homens e mulheres para direitos civis e políticos, nos termos do art. $3^{\circ}$. Além deste, a Declaração de Direitos Humanos de Viena, de 1993, estabeleceu a proteção aos direitos das mulheres e das meninas.

A Convenção sobre a Eliminação de Todas as Formas de Discriminação Contra a Mulher foi adotada pela Assembleia Geral das Nações Unidas em 1979, e entrou em vigor em 1981, quando o $11^{\circ}$ Estado assinou a convenção. No Brasil foi ratificada em 1994. A Convenção define o que é discriminação contra a mulher, estabelecendo mais do que violência física, mas distinção, exclusão ou restrição baseada no sexo com objetivo ou resultado de prejudicar ou anular reconhecimento, gozo ou exercício pela mulher dos direitos humanos e liberdades fundamentais. Ainda, prevê que a discriminação pode ocorrer no campo político, econômico, social, cultural, civil ou outro qualquer. Com base nessa Convenção, os Estados Membros concordam em adotar uma série de medidas para acabar com a discriminação, sendo as negativas, aquelas que propicíam a fruição do direito, e positivas, mudanças legislativas, por exemplo. Em 2002, foi ratificado pelo Brasil o Protocolo Facultativo à CEDAW, que prevê competência do Comitê para receber comunicações por indivíduos ou grupos sobre desrespeito às normas da Convenção.

Com base na CEDAW e seu protocolo adicional a proteção é feita, além das obrigações impostas ao Estado, pelo Comitê que examina relatórios periódicos apresentados pelos Estados Partes e apresenta recomendações, instaura inquéritos confidenciais e examina comunicações quando ocorrer uma violação.

Já a Convenção Interamericana para Prevenir, Punir e Erradicar a Violência contra a Mulher (Convenção de Belém do Pará), adotada em 1994, protege as mulheres de violências no âmbito regional interamericano, tanto na esfera pública quanto privada. Essa convenção também prevê várias imposições aos Estados não apenas na esfera de violência física, mas para estabelecer direito a igual proteção perante a lei, liberdades sociais e profissionais. No art. $5^{\circ}$ é disposto sobre o direito da mulher em exercer direitos civis, políticos, econômicos, sociais e culturais. No art. $8^{\circ}$, é imposto aos Estados adotar programas de promoção dos direitos das mulheres e conscientização social. 
Outra importante proteção é a Resolução do Conselho de Direitos Humanos n. 41/2 de 2010 da ONU que demanda dos Estados o estabelecimento de planos de ação para combate à violência contra mulheres, bem como contemplarem mecanismos de accountability. (PIOVESAN, 2014).

\section{Jurisprudência Internacional}

Notável que, não obstante os esforços legislativos internacional e nacional, ainda não se concretizou uma sociedade igualitária. Mas, continua se perpetuando o modelo patriarcal. Isso é observado desde os números alarmantes de violências contra as mulheres no Brasil, sendo que, apenas em 2017, conforme o G1, houve mais de quatro mil mortes por feminicídio (VELASCO; CAESAR; REIS, 2018), para os casos relatados diariamente, sendo que alguns, devido à gravidade e descaso do Estado, chegam a ser analisados pelos órgãos internacionais.

Um caso recente é o da advogada Tatiane Spitzner onde o relatório da polícia aponta ainda que, além dessas agressões, há indícios de que foi esganada pelo seu marido Luís Felipe Manvailer; um caso recente e que nos traz a realidade de que a violência se faz presente em todos os lares desde os mais humildes até os mais sofisticados, não somente no que diz respeito à questão financeira, mas, também, pelo grau de instrução.

Quanto a caso levado a órgão internacional, expõe-se o caso Alyne Pimentel vs. Brasil. Esse caso foi representado por Maria de Lourdes da Silva Pimentel, em 2008, por comunicação individual contra o Brasil diante do Comitê CEDAW. A comunicação alegava violação ao direito à saúde e à vida, ineficiência de prestação jurisdicional contra discriminação de gênero, sistêmica condição de discriminação de gênero e violação do direito à saúde das mulheres pela ineficiência dos serviços médicos. Isto se deu, pois em 2002 Alyne Pimentel, grávida de seis meses, compareceu na Casa de Saúde Nossa Senhora da Glória, unidade conveniada ao SUS, reclamando de náusea e dores abdominais. A vítima foi atendida por ginecologista, mas não foram realizados exames laboratoriais ou de ultrassonografia; apenas coleta de sangue e urina para serem feitos dois dias depois.

Quando retornou à Casa de Saúde, Alyne estava com dores ainda mais intensas e ao ser examinada por outros médicos, foi identificada a morte do feto. Assim, foi submetida a parto induzido para sua retirada. Porém, o parto não foi bem-sucedido e ocorreu uma cirurgia de curetagem, transcorridos em período de 14 horas entre os procedimentos. Como a condição dela piorou, a equipe médica buscou outros hospitais mais bem equipados para receber a paciente.

Como o único hospital disponível se recusou a fornecer transporte adequado, e a mãe de Alyne não podia arcar com uma ambulância particular, teve que aguardar carro da rede pública, o que levou oito horas. Ao chegar no outro hospital, a 
Casa de Saúde omitiu as informações sobre o estado de saúde da paciente e não enviou os registros médicos. Resultado, alguns dias depois, Alyne faleceu. Solicitado pelo hospital, a mãe de Alyne compareceu à Casa de Saúde para obter o prontuário médico, sendo que lá descobriu que o feto estava morto há dias, causando a morte de Alyne.

Após regular trâmite, o Comitê CEDAW entendeu que a morte de Alyne foi morte materna e considerou que o Brasil violou: acesso à saúde (art. 12), acesso à justiça (art. $2^{\circ}$, c e art. $1^{\circ}$ ).

Ainda, recomendou ao Estado brasileiro: garantir a reparação apropriada, inclusive financeira, para mãe e filha da vítima, bem como:

\begin{abstract}
garanta o direito das mulheres à maternidade segura e a preços acessíveis, aos cuidados obstétricos de emergência; reduza as mortes maternas evitáveis por meio da implementação do Pacto Nacional pela Redução da Mortalidade Materna no nível estadual e municipal, incluindo a criação de comitês de mortalidade materna onde eles ainda não existam; ofereça treinamento profissional adequado para os profissionais de saúde, especialmente sobre os direitos das mulheres à saúde reprodutiva; assegure que os serviços de saúde privados cumpram com padrões nacionais e internacionais relevantes de assistência à saúde reprodutiva; assegure que sanções adequadas sejam impostas aos profissionais de saúde que violem os direitos relacionados à saúde reprodutiva das mulheres; e assegure o acesso à proteção jurídica adequada e efetiva em casos em que os direitos relativos à saúde reprodutiva das mulheres tenham sido violados. (CATOIA; SEVERI; FIRMINO, 2020, p. 6).
\end{abstract}

Portanto, nota-se que ainda há um longo caminho a se percorrer para alcançar a igualdade efetiva, ou, inclusive, para diminuir a violência constante realizada contra a mulher. Uma das causas para isso vão além de medidas legislativas, que são muito pouco eficazes se não forem complementadas por medidas de mudança da mentalidade da sociedade.

\title{
5. O homem como vítima da cultural patriarcal.
}

O que sustenta o comportamento machista e controlador na sociedade nada mais é que um legado estruturado de controle e poder pelo simples fato de nascer homem; nascer homem já rendia uma herança de alguns "privilégios" na sociedade, ou seja, ainda existe na sociedade, se não no mundo, o pensamento de que o homem é melhor, mais forte, mais inteligente, mais esperto, o que de fato não condiz com a realidade.

Contudo, essa sociedade machista, igualmente prejudica os homens, devido a esses estereótipos de força, que leva a cobrar uma ausência de emoção, não 
poder demonstrar fragilidade, não poder sentir. Isso é evidenciado por novas pesquisas que demonstram que a maioria das vezes que houve violência sexual contra homens, esses não revelam ao público e, se o fazem, levam em média mais de 10 anos. Esses dados são em razão da imposição da sociedade de sempre ter o homem como um ser forte. O mais alarmante é que normalmente a violência sexual contra homens ocorre na infância, ou seja, a criança já é extremamente afetada por esses estigmas.

Em Portugal, foi criada uma associação "Associação Quebrar o Silêncio" que presta apoio especializado a homens que sofreram abuso sexual. Os dados desse projeto mostram que a maioria dos homens que buscam ajuda estão fazendo isso pela primeira vez ( $78 \%$ dos casos recebidos). Também foi observado no projeto que a maioria das pessoas atendidas procuram apoio após 20 ou 30 anos do ocorrido. (FLOR, 2019).

Isso mostra que a sociedade leva à perpetuação contínua dos conceitos patriarcais, ou seja, a um ciclo muito danoso. A criança aprende desde cedo seu papel como "macho, forte, insensível e machista", sofre durante sua vida; violenta a mulher (não necessariamente fisicamente, podendo apenas compreendê-la como ser inferior) e transmitindo esse comportamento às futuras gerações.

\section{Considerações finais}

Neste sentido, nota-se que grande parte do problema não está nas medidas legislativas, as quais já existem em plenitude, mas sim na mudança da sociedade. Para que essa mudança ocorra, é de extrema importância que se volte os olhos para o gênero masculino, a fim de abolir os tradicionais estereótipos dos quais eles sofrem, quebrando -se com isso o ciclo.

Observa-se que isto já está previsto, com outras palavras, tanto na Convenção de Belém do Pará, quanto na CEDAW. A Belém do Pará prevê:

\section{Artigo 8}

Os Estados Partes convêm em adotar, progressivamente, medidas específicas, inclusive programas destinados a:

b. modificar os padrões sociais e culturais de conduta de homens e mulheres, inclusive a formulação de programas formais e não formais adequados a todos os níveis do processo educacional, a fim de combater preconceitos e costumes e todas as outras práticas baseadas na premissa da inferioridade ou superioridade de qualquer dos gêneros ou nos papéis estereotipados para o homem e a mulher, que legitimem ou exacerbam a violência contra a mulher; 


\section{Enquanto a CEDAW dispõe:}

Artigo 5

Os Estados-partes tomarão todas as medidas apropriadas para:

a) modificar os padrões sócio-culturais de conduta de homens e mulheres, com vistas a alcançar a eliminação dos preconceitos e práticas consuetudinárias, e de qualquer outra índole que estejam baseados na idéia de inferioridade ou superioridade de qualquer dos sexos ou em funções estereotipadas de homens e mulheres;

Porém, essas disposições na prática foram colocadas de lado, dando espaço apenas às mudanças legislativas. Como uma não pode ser concretizada sem a outra, e, por já existir as medidas protetivas legislativas, deve-se dar atenção, no momento, a medidas educacionais, de mudança de paradigmas, para ensinar aos homens, especialmente na infância a quebrar os padrões da sociedade falocêntrica. Ainda, devem focar em programas de proteção aos meninos na infância para serem protegidos dessa mentalidade, a qual é de extrema prejudicialidade para eles, uma vez que se abusados sentem que não podem denunciar.

Curitiba, abril de 2020.

\section{Referências}

BRASIL. [Constituição (1988)]. Constituição da República Federativa do Brasil de 1988. Portal do Planalto, Brasília, DF, 5 out. 1988. Disponível em: http://www.planalto.gov.br/ccivil_03/ constituicao/constituicao.htm.

BRASIL. Decreto-Lei n. 2.848, de 7 de dezembro de 1940. Código Penal. Portal do Planalto, Brasília, DF, 31 dez. 1940. Disponível em: http://www.planalto.gov.br/ccivil_03/decreto-lei/ del2848.htm.

BRASIL. Lei n. 10.406, de 10 de janeiro de 2002. Institui o Código Civil. Portal do Planalto, Brasília, DF, 11 jan. 2002. Disponível em: http://www.planalto.gov.br/ccivil_03/leis/2002/ 110406compilada.htm.

BRASIL. Lei n. 3.071, de $1^{\circ}$ de janeiro de 1916. Código Civil dos Estados Unidos do Brasil. Portal do Planalto, Brasília, DF, 5 jan. 1916. Disponível em: http://www.planalto.gov.br/ccivil_03/leis/ 13071.htm.

BRASIL. Lei n. 4.121, de 27 de agosto de 1962. Dispõe sôbre a situação jurídica da mulher casada. Portal do Planalto, Brasília, DF, 3 set. 1962. Disponível em: http://www.planalto.gov.br/ccivil_03/ leis/1950-1969/L4121.htm. 
BRASIL. Lei n. 6.515, de 26 de dezembro de 1977. Regula os casos de dissolução da sociedade conjugal e do casamento, seus efeitos e respectivos processos, e dá outras providências. Portal do Planalto, Brasília, DF, 27 dez. 1977. Disponível em: http://www.planalto.gov.br/ccivil_03/leis/ 16515.htm.

CATOIA, Cinthia de Cassia; SEVERI, Fabiana Cristina; FIRMINO, Inara Flora Cipriano. Caso "Alyne Pimentel": violência de gênero e interseccionalidades. Revista Estudos Feministas, Florianópolis, v. 28, n. 1, 11 p., 2020.

CEDAW. Committee on the elimination of discrimination against women. Forty-ninth session. C/49/D/17/2008. [S. l.: s. n.], 29 July 2011. Disponível em: https://www2.ohchr.org/english/law/ docs/CEDAW-C-49-D-17-2008.pdf.

FLOR, Aline. Os homens também são vítimas de abuso sexual e há uma associação que já ajudou 146. Público, Lisboa, 18 jan. 2019. Disponível em: https:/www.publico.pt/2019/01/18/sociedade/ noticia/quebrar-silencio-violencia-sexual-homens-1858331. Acesso em: 10 out. 2019.

HACKER, Helen Mayer. Women as a minority group. Social Forces, Cary, v. 30, n. 1, p. 60-69, Oct. 1951.

HASSE, Mariana. Violência de gênero contra mulheres: em busca da produção de um cuidado integral. 2016. Tese (Doutorado em Enfermagem) - Enfermagem, Universidade de São Paulo, São Paulo. 2016.

JAIN, Pratibha. Balancing minority rights and gender justice: the impact of protecting multiculturalism on women's rights in India. Berkeley Journal of International Law, Berkley, CA, v. 23, n. 1, p. 201-222, 2005.

LAQUEUR, Thomas Walter. Inventando o sexo: corpo e gênero dos gregos a Freud. Rio de Janeiro: Relume Dumará, 2001.

LEÃO, Beatriz do Brasil Volpi; PEDROZO, Luiz Henrique Batista de Oliveira. A evolução legislativa dos direitos femininos pós Constituição Federal de 1988 e a sua relação com os movimentos feministas. In: POZZOLI, Lafayette; SILVA, Diego Nassif da; STIPP, Luna (org.). Histórias e teorias críticas do direito. 1. ed. Jacarezinho, PR: UENP, 2018. p. 20- 40.

MARTINS, Argemiro Cardoso Moreira; MIZUTANI, Larissa. Direito das minorias interpretado: o compromisso democrático do direito brasileiro. Seqüência: Estudos Jurídicos e Políticos, Florianópolis, v. 32, n. 63, p. 319-352, dez. 2011.

NAÇÕES UNIDAS. Convenção sobre a eliminação de todas as formas de discriminação contra as mulheres. Nova York, 18 dez. 1979. Disponível em: https://unesdoc.unesco.org/ark:/48223/ pf0000139389.

NAÇÕES UNIDAS. Declaração Universal dos Direitos Humanos. Paris, 10 dez. 1948. Disponível em: http://www.cne.pt/sites/default/files/dl/1_declaracao_universal_direitos_homem.pdf. 
NAÇÕES UNIDAS. Pacto Internacional dos Direitos Civis e Politicos. Nova York, 16 dez. 1966. Disponível em: https://www.oas.org/dil/port/1966\%20Pacto\%20Internacional\%20sobre\%20 Direitos\%20Civis\%20e\%20Pol\%C3\%ADticos.pdf.

NAÇÕES UNIDAS. Protocolo facultativo à Convenção sobre a eliminação de todas as formas de discriminação contra as mulheres. New York, 6 out. 1999. Disponível em: https://www.oas.org/ dil/port/1999\%20Protocolo\%20Facultativo\%20\%C3\%A0\%20Conven $\%$ C3\%A7\%C3\%A30\%20 sobre $\% 20$ a $\% 20$ Elimina $\%$ C3\%A7\%C3\%A3o\%20de $\% 20$ Todas $\% 20$ as $\% 20$ Formas $\% 20 \mathrm{de} \% 20$ Discrimina\%C3\%A7\%C3\%A3o\%20contra\%20as\%20Mulheres.pdf.

OLIVA, Thiago Dias; KÜNZLI, Willi Sebastian. Proteção das minorias no direito internacional. Revista da Faculdade de Direito da Universidade de São Paulo, São Paulo, v. 113. p. 703-719, jan./ dez. 2018.

ORGANIZAÇÃO DOS ESTADOS AMERICANOS. Convenção de Belém do Pará. Belém, 9 junho 1944. Disponível em: http://www.cidh.org/Basicos/Portugues/m.Belem.do.Para.htm.

PIOVESAN, Flávia. A proteção internacional dos direitos humanos das mulheres. Cadernos Jurídicos, São Paulo, ano 15, n. 38, p. 21-34, jan./abr. 2014.

SANTIAGO, Rosilene Almeida; COELHO, Maria Thereza Ávila Dantas. A violência contra a mulher: antecedentes históricos. Seminário Estudantil de Produção Acadêmica: SEPA, Salvador, v. 11, n. 1, 2007.

VELASCO, Clara; CAESAR, Gabriela; REIS, Thiago. Cresce o ${ }^{\circ}$ de mulheres vítimas de homicídio no Brasil; dados de feminicídios são subnotificados. G1, [s. l.], 7 mar. 2018. Disponível em: https:// g1.globo.com/monitor-da-violencia/noticia/cresce-n-de-mulheres-vitimas-de-homicidio-no-brasildados-de-feminicidio-sao-subnotificados.ghtml.

VERONESE, Yasmim Leandro. A evolução histórica dos direitos femininos e a Lei Maria da Penha. ETIC: Encontro de Iniciação Científica, Presidente Prudente, v. 7, n. 7, 12 p., 2011. Disponível em: http://intertemas.toledoprudente.edu.br/index.php/ETIC/article/view/4268/4026. 